\title{
INFLUENCE OF PH AND CALCINATION TEMPERATURE ON MAGNETIC PROPERTIES OF NANOSIZED ZN-FERRITE SYNTHESIZED BY SOL-GEL CITRATE METHOD
}

\author{
Samarjit Singh ${ }^{1}$, Gaurav Goswami ${ }^{2}$, Abhishek Kumar ${ }^{3}$ \\ ${ }^{I}$ Department of Applied Mechanics, MNNIT Allahabad, Allahabad-211004 \\ ${ }^{2}$ Department of Applied Mechanics, MNNIT Allahabad, Allahabad-211004 \\ ${ }^{3}$ Department of Applied Mechanics, MNNIT Allahabad, Allahabad-211004
}

\begin{abstract}
The present research has been motivated by the potential use of ferrites in the technological advancement of advanced electronic and magnetic devices. Sol-gel citrate method has been employed to synthesize Zn-ferrite at different values of pH viz., 3, 5, 7, 9 and 12; and subsequently the effect of calcination temperatures viz., 600, 700 and $800{ }^{\circ} \mathrm{C}$ on the particle morphology and magnetic behavior was studied for the sample prepared at $\mathrm{pH}$ 9. X-ray diffraction (XRD) analysis has been carried out to investigate the effect of $\mathrm{pH}$ and calcination temperatures on the desired spinel phase formation behavior and its magnetic properties. Although the formation of different phases has started from $\mathrm{pH} 5$, single phase could be observed only when pH has reached a value of 9. From XRD and FE-SEM characterization of the calcined powder, it has been found that with the increase in calcination temperature particle size increases. B-H curves of the prepared ferrite powders showed that magnetic properties are sensitive to both the $\mathrm{pH}$ of the solution and calcination temperature.
\end{abstract}

Keywords: Zn-ferrite, Sol-Gel Citrate Method, Effect of pH, Calcination temperature, Magnetic properties.

\section{INTRODUCTION}

Spinel ferrites have been widely used in many technological applications because of their excellent optical, electronic and magnetic properties for last many years [1,2]. Recent advances in the synthesis techniques for the production of ferrites have initiated interest in ferrites in order to improve their physical properties and expand their applications [1]. With the fast growing technology, the electronic components with small size, high efficiency, and low cost are urgently demanded [3]. Ferrites are technologically important and have been used in many applications like magnetic recording media for the storage and/or retrieval of information, magnetic resonance imaging (MRI) enhancement, catalysis, magnetically guided drug delivery, multilayer chip inductor, sensors, pigments, transformer cores, etc. $[4,5]$. Requirement of desirable microstructure: a high sintered density, a small particle size and a narrow particle size distribution is important in such applications [6]. Among ferrites, Zinc ferrite $\left(\mathrm{ZnFe}_{2} \mathrm{O}_{4}\right)$ is of particular interest because of its use as a magnetic material, thereby, requirement of fine control over its crystal size, crystallinity and phase purity of the nano-powder are important [7-9]. Phase formation, particle size and morphology of the ferrite powder depend on $\mathrm{pH}$ value of the initial solution, molar ratio of the ions and calcination temperature. Various preparation methods have been developed to obtain nanosized ferrite particles, including a chemical process, coprecipitation, mechanical alloying, sol-gel method, hydrothermal and ball milling methods [10]. In every synthesis route, process parameters are responsible for the difference in the microstructure and properties of the final product. In sol-gel method, $\mathrm{pH}$ of the initial solution, molar ratio of the participating ions and calcination temperature affect the properties of the final product. In the present study, influence of the variation in $\mathrm{pH}$ and calcination temperature has been studied using sol-gel citrate method.

\section{EXPERIMENTAL METHODOLOGY}

The $\mathrm{ZnFe}_{2} \mathrm{O}_{4}$ nano-crystalline powder was synthesized by sol-gel citrate method using analytical grade of $\mathrm{Fe}\left(\mathrm{NO}_{3}\right)_{3} .9 \mathrm{H}_{2} \mathrm{O}$ and $\left(\mathrm{CH}_{3} \mathrm{COO}\right)_{2} \mathrm{Zn} .2 \mathrm{H}_{2} \mathrm{O}$ reagent. The flow chart shown in Fig. 1 gives the experimental procedure that has been carried out. Stoichiometric amount of metal nitrate were dissolved completely in double distilled water to make an aqueous solution and then aqueous solution of citric acid was mixed with it in 1:1 molar ratio and subjected to constant stirring for $1 \mathrm{~h}$ with the help of magnetic stirrer. The solutions with five different $\mathrm{pH}$ values viz., 3, 5, 7, 9 and 12 were prepared. The $\mathrm{pH}$ adjustment was done by the addition of liquid ammonium in the solution under constant stirring. After this the solution was kept in an oven at $80^{\circ} \mathrm{C}$ for $2-3 \mathrm{~h}$ to reduce its volume to about $25 \%$. Remaining solution after evaporation was hot stirred at $70-80{ }^{\circ} \mathrm{C}$ till the gel formation. In the subsequent step, the obtained gel was calcined at $750{ }^{\circ} \mathrm{C}$ for $10 \mathrm{~h}$ to obtain polycrystalline $\mathrm{ZnFe}_{2} \mathrm{O}_{4}$ powder. To see the effect of calcination temperature, sample prepared at $\mathrm{pH} 9$ was calcined at 600 , 700 and $800{ }^{\circ} \mathrm{C}$ for $5 \mathrm{~h}$ each. 
The crystalline phase present in the calcined powder was identified by X-ray diffraction using Bruker AXS D8 diffractometer with $\mathrm{Cu}-\mathrm{K}_{\square}$ radiation. The crystallite size of the powder was measured by X-ray line broadening technique employing Scherrer's formula. The dried gel precursors were characterized via Thermogravimetric Analyzer (TGA) using Perkin Elmer, Pyris Diamond, USA. The surface morphology of the synthesized nanoparticles were studied by FE-SEM using QUANTA FEG 200 FEI and magnetic properties were measured at room temperature in the applied field range of $-18,000$ Oe to $+18,000$ Oe by means of Vibrating Sample Magnetometer, VSM (155, PAR).

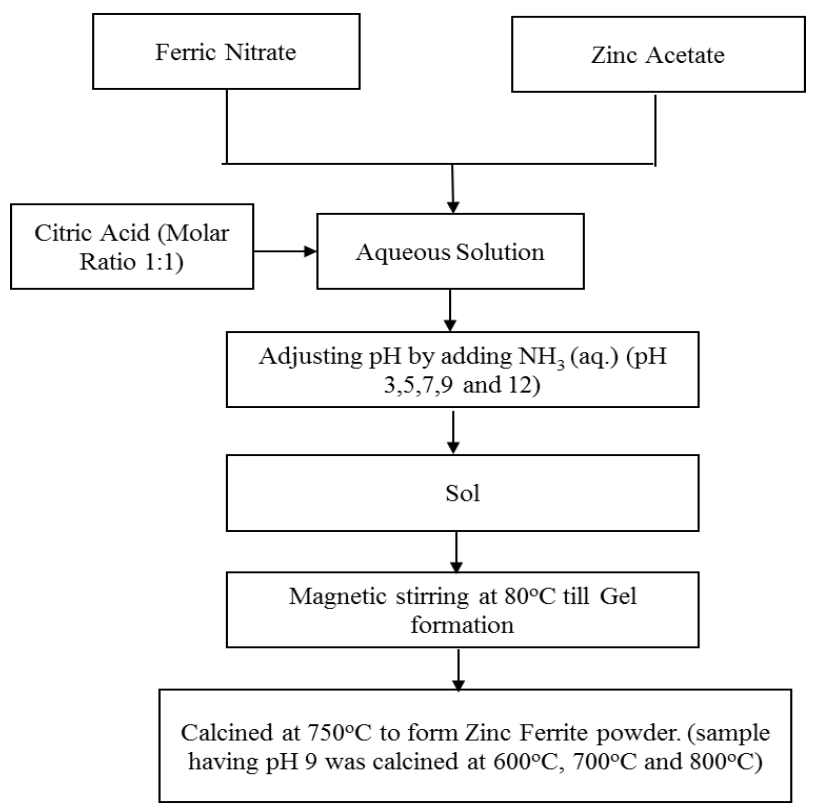

Fig 1: Flow chart showing the citric acid assisted sol-gel synthesis of $\mathrm{ZnFe}_{2} \mathrm{O}_{4}$ powder.

\section{RESULTS AND DISCUSSION}

\subsection{Effect of $\mathbf{p H}$}

The indexed XRD patterns of the $\mathrm{ZnFe}_{2} \mathrm{O}_{4}$ nanoparticles synthesized at different $\mathrm{pH}$ value and heat treated at $750^{\circ} \mathrm{C}$ for $10 \mathrm{~h}$. in the air atmosphere has been shown in Fig. 2. The different phases present in the XRD pattern were identified with the help of JCPDS card number. From the XRD pattern of the material produced with solution having $\mathrm{pH} 3$, $\mathrm{ZnFe}_{2} \mathrm{O}_{4}$ phase could be detected along with other minor phases but the crystallinity was found to be low. While the powder prepared from the solutions of $\mathrm{pH}>5$ were having major crystalline zinc ferrite phases denoted by $\square \square$ along with other minor phases. At pH 5 and 7, some minor phases of $\mathrm{ZnO}$ and $\mathrm{Fe}_{2} \mathrm{O}_{3}$ denoted by $\beta$ and $\gamma$ respectively were observed due to incomplete chelation of metallic ions in the solution while comparing with that of pure zinc ferrite phase obtained at $\mathrm{pH} 9$ and $\mathrm{pH} 12$ respectively. As per literature reported dissociation of minor phases could be obtained by calcination at higher temperatures.

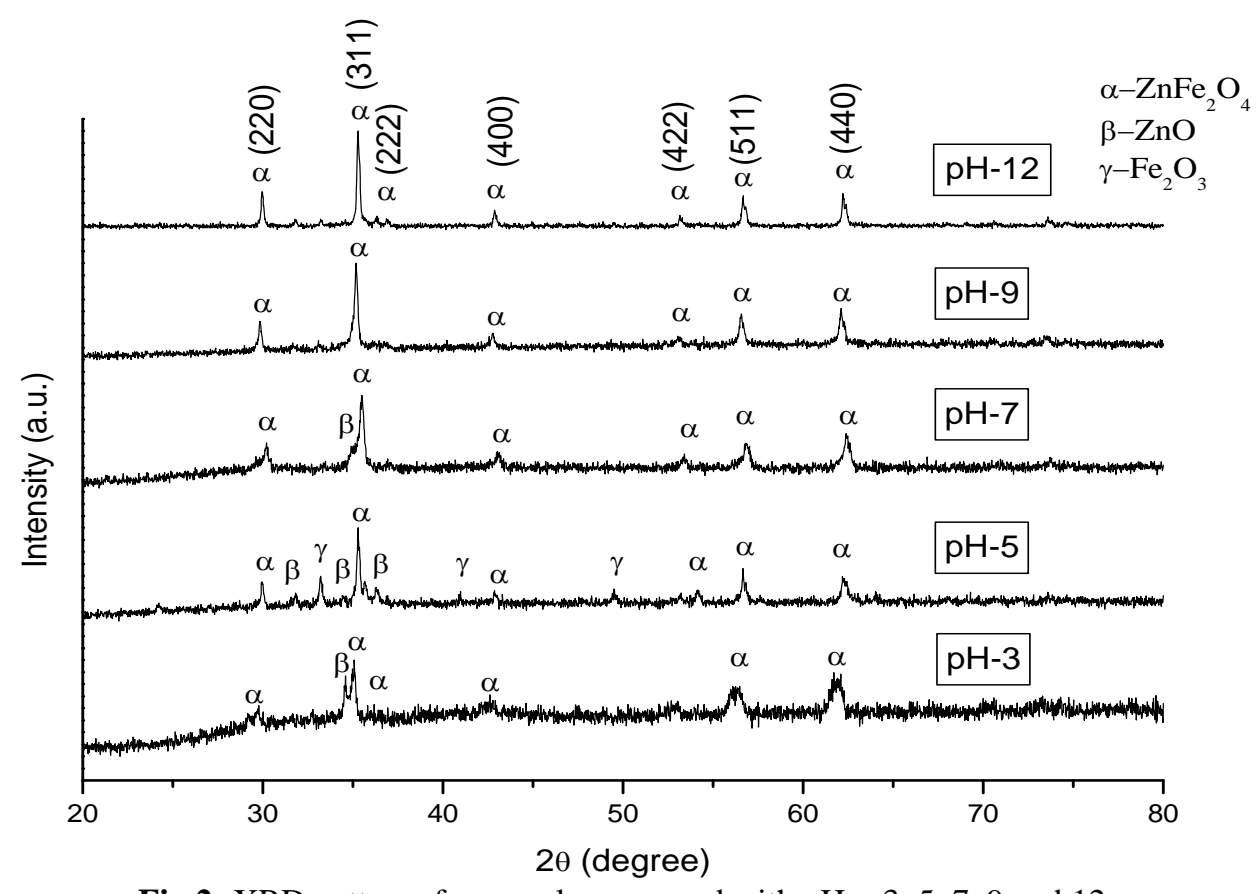

Fig 2: XRD patterns for samples prepared with $\mathrm{pH}=3,5,7,9$ and 12. 
XRD pattern of different calcined powder with different $\mathrm{pH}$ values shows that the $\mathrm{pH}$ affects the process reactions significantly as well as phase formation. Average crystallite size of different calcined powder using Scherrer's equation varied from $22-44 \mathrm{~nm}$.

The FE-SEM photomicrographs of calcined powders obtained from the solutions of different $\mathrm{pH}$ values are shown in Fig. 3. It is interesting to note that the $\mathrm{pH}$ value has a

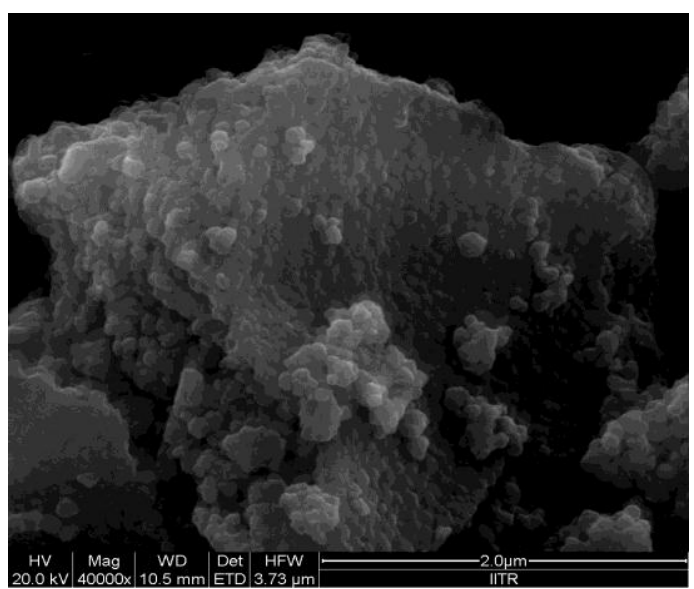

(a)

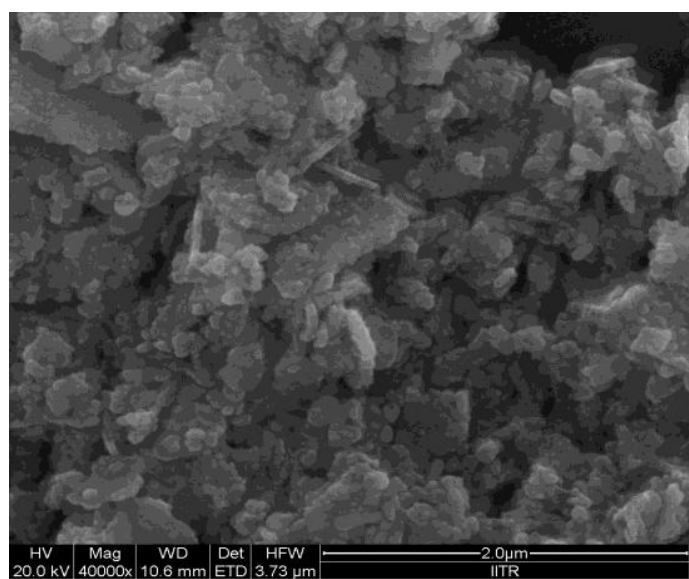

(c) significant influence on the morphology of the calcined powder. It is found that the crystallite size of powder is more fairly uniform in case of $\mathrm{pH}$ 9. The micrographs of $\mathrm{ZnFe}_{2} \mathrm{O}_{4}$ show that the powders have a fine structure which is a justification of broad peaks in observed in XRD results. Another important conclusion from FE-SEM micrographs is that at higher values of $\mathrm{pH}$, the agglomeration tendency of the ferrite nanoparticles increases which is quite evident from Fig. 3(e).

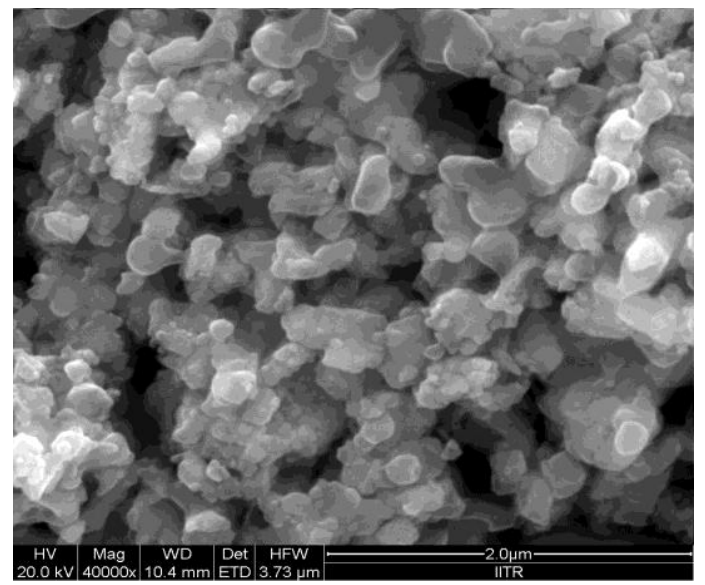

(b)

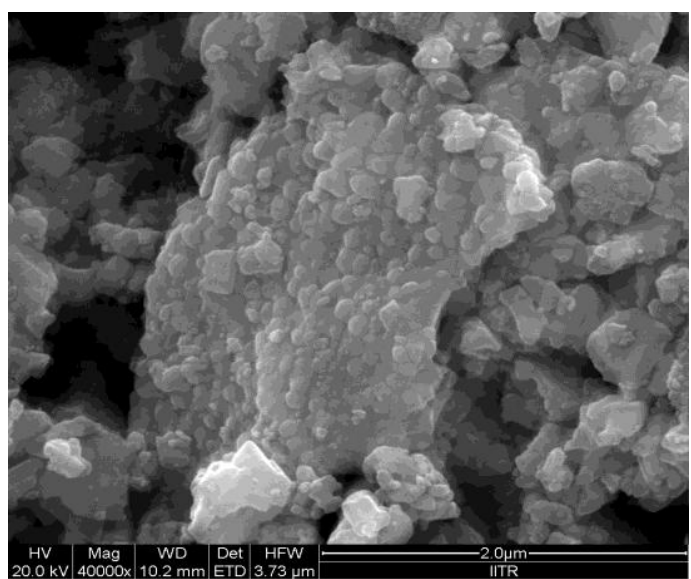

(d)

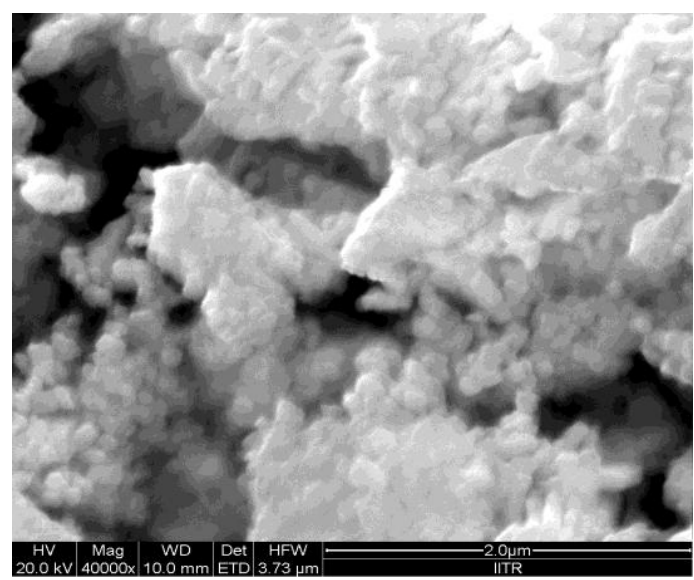

(e)

Fig 3: FE-SEM micrographs of $\mathrm{ZnFe}_{2} \mathrm{O}_{4}$ synthesized with different $\mathrm{pH}$ values: (a) $\mathrm{pH} 3$, (b) $\mathrm{pH}$ 5, (c) $\mathrm{pH}$ 7, (d) $\mathrm{pH} 9$ and (e) $\mathrm{pH}$ 12 
Fig. 4 shows the magnetic properties of the calcined powders synthesized at varying $\mathrm{pH}$ values. It has been found, from the hysteresis curve that the magnetic properties are also affected with the change in $\mathrm{pH}$ of the solutions. The change in magnetic properties may be attributed to the presence of multiple phase and variation in particle size in case of $\mathrm{pH} 5$ and $\mathrm{pH} 7$ and variation of crystallite size in case of $\mathrm{pH} 9$ and $\mathrm{pH} 12$.

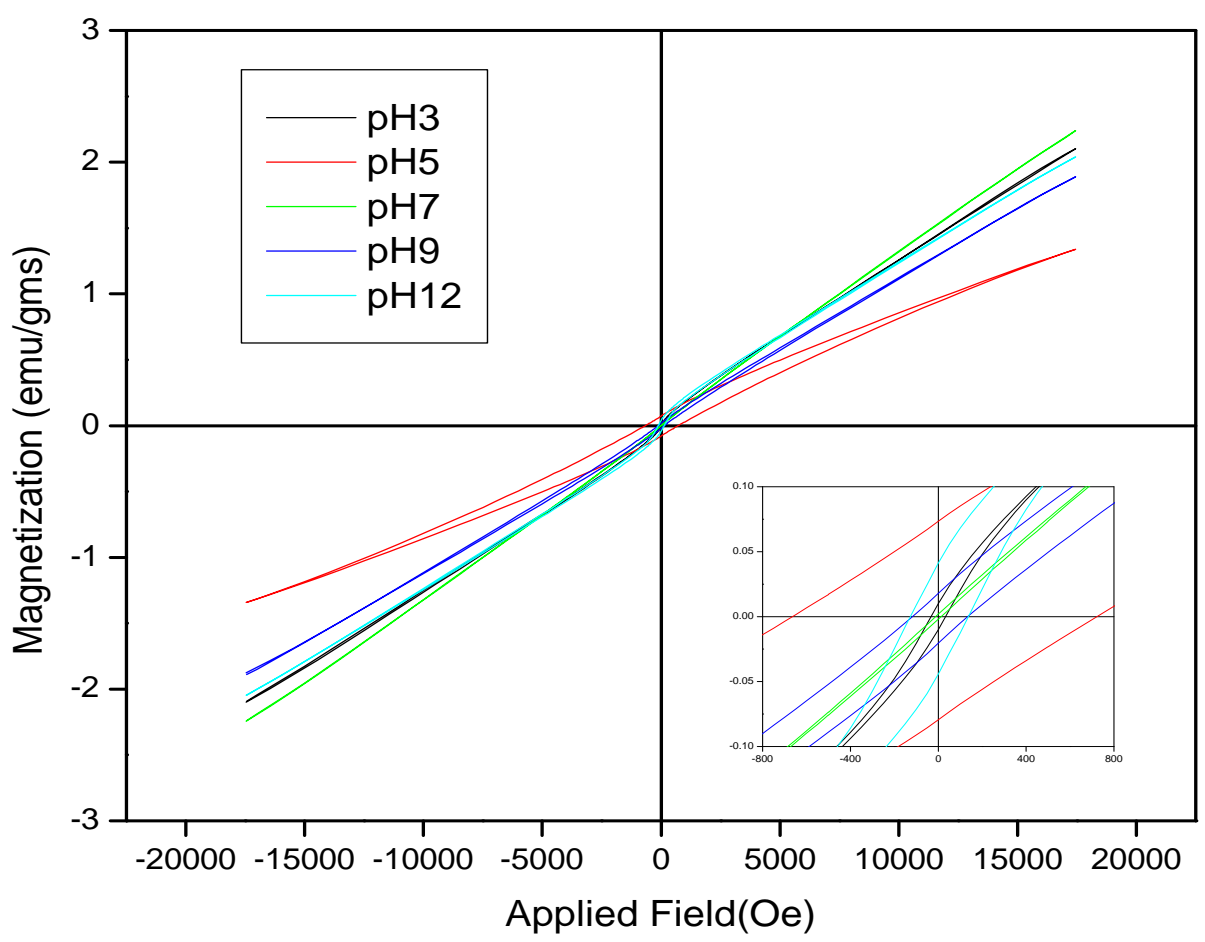

Fig 4: Effect of $\mathrm{pH}$ variation on magnetic properties of $\mathrm{ZnFe}_{2} \mathrm{O}_{4}$ at room temperature.

\subsection{Effect of Calcination Temperature}

The Differential Thermal Analysis, Differential Thermogravimetry, and Thermogravimetry (DTA/DTG/TG) traces of the powder prepared at $\mathrm{pH} 9$ was carried out at the heating rate of $10{ }^{\circ} \mathrm{C} / \mathrm{min}$ in air atmosphere is shown in Fig. 5. As the TG/DTG traces are concerned, two step mass loss phenomenon is present. The first step of mass loss (ending at $\approx 200{ }^{\circ} \mathrm{C}$ ) is due to the dehydration of zinc acetate. The second step ends at $\approx 350{ }^{\circ} \mathrm{C}$ and corresponds to a mass of nearly $66 \%$. During this step both dehydration and decomposition (with partial oxidation) occurs. As the DTA traces are concerned, two exothermic peaks are present. The first one has an enthalpy of $-96.6 \mathrm{~mJ} / \mathrm{mg}$ and second has an enthalpy of $-3.33 \mathrm{~J} / \mathrm{mg}$. The mass loss under first peak is much lower than second peak. The excess of exothermic enthalpy is attributed to the formation of $\mathrm{ZnFe}_{2} \mathrm{O}_{4}$.

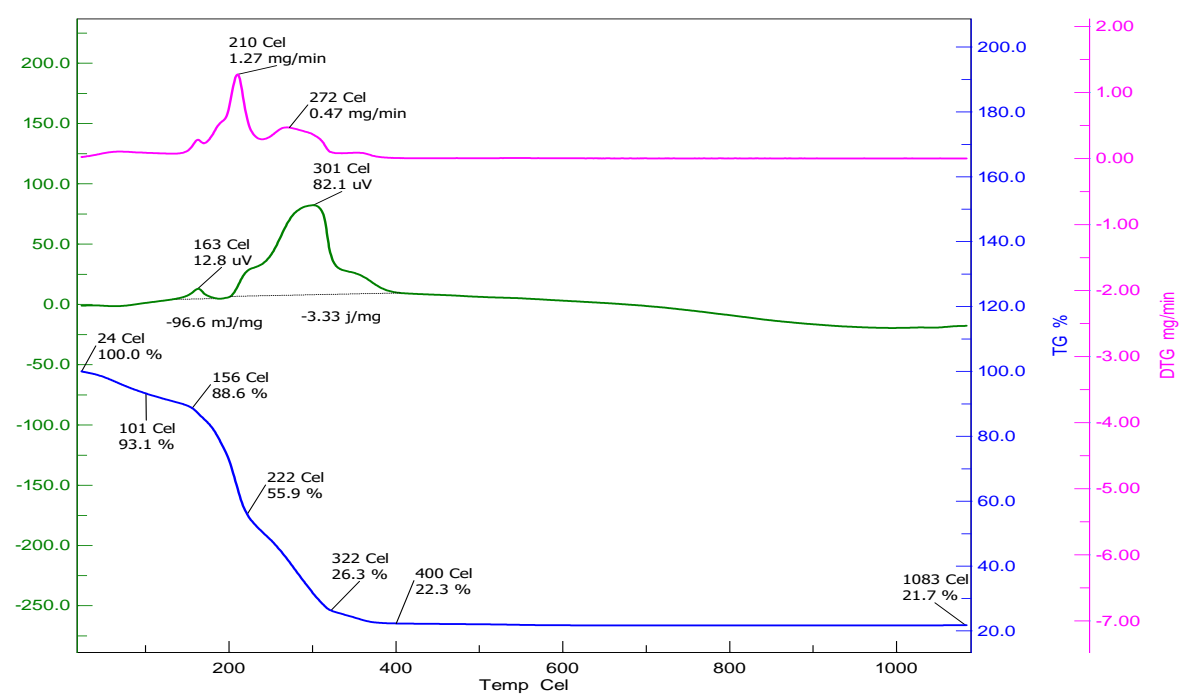

Fig 5: TG-DTA-DTG curve for the gel precursor prepared by heating the solution of $\mathrm{pH} 9$. 
Fig. 6 shows the XRD pattern of powders calcined at different temperature. All the peaks in the XRD pattern at different calcination temperature corresponds to the JCPDS card no. 89-1012 and confirm the formation of single phase of $\mathrm{ZnFe}_{2} \mathrm{O}_{4}$.

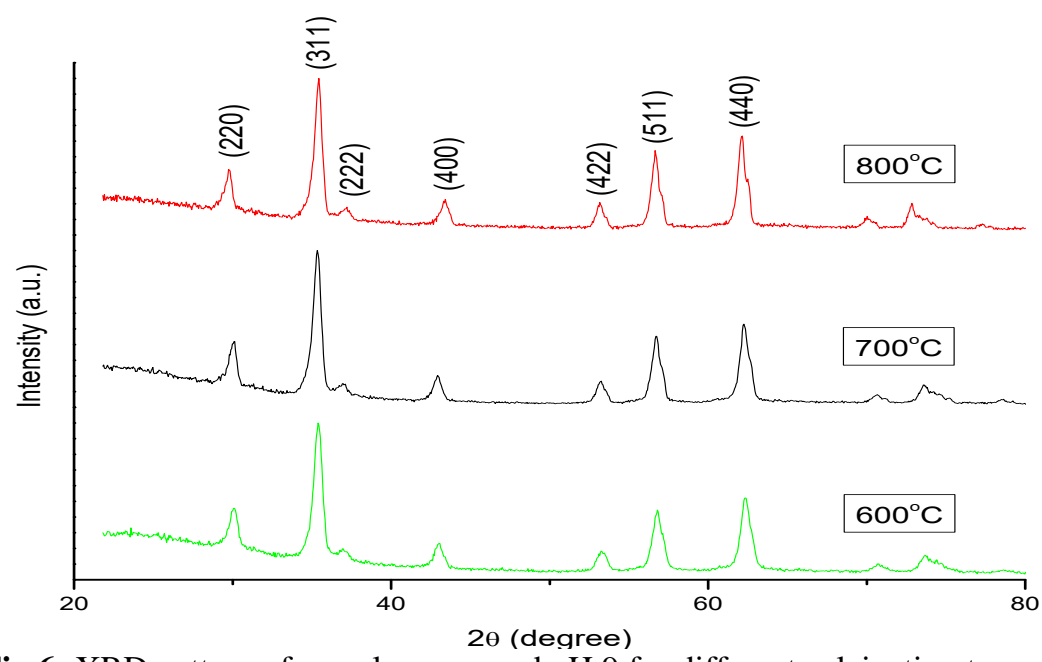

Fig 6: XRD pattern of samples prepared $\mathrm{pH} 9$ for different calcination temperature.

The crystallite sizes obtained from the XRD pattern for the samples calcined at 600,700 and $800{ }^{\circ} \mathrm{C}$, are shown in Table 2.

Table 2: Crystallite size at different calcination temperature

\begin{tabular}{|l|l|l|l|}
\hline Calcination temperature & $600{ }^{\circ} \mathrm{C}$ & $700{ }^{\circ} \mathrm{C}$ & $800{ }^{\circ} \mathrm{C}$ \\
\hline Crystallite size $(\mathrm{nm})$ & 14 & 16 & 21 \\
\hline
\end{tabular}

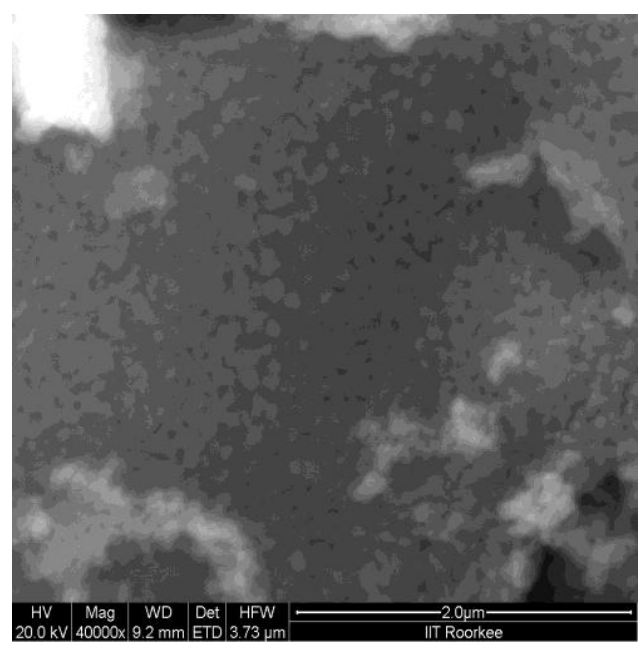

(a)
Fig. 7 shows the FE-SEM images of synthesized Zinc ferrite powder calcined at 600,700 and $800{ }^{\circ} \mathrm{C}$. SEM analysis depicts the nanosized particle formation. It is found from FE-SEM micrographs that particles were spherical in shape and particle size increases with calcination temperature.

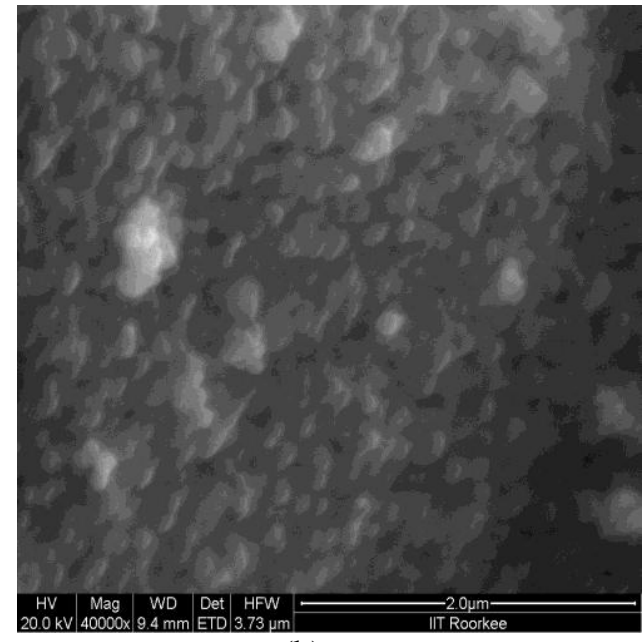

(b) 


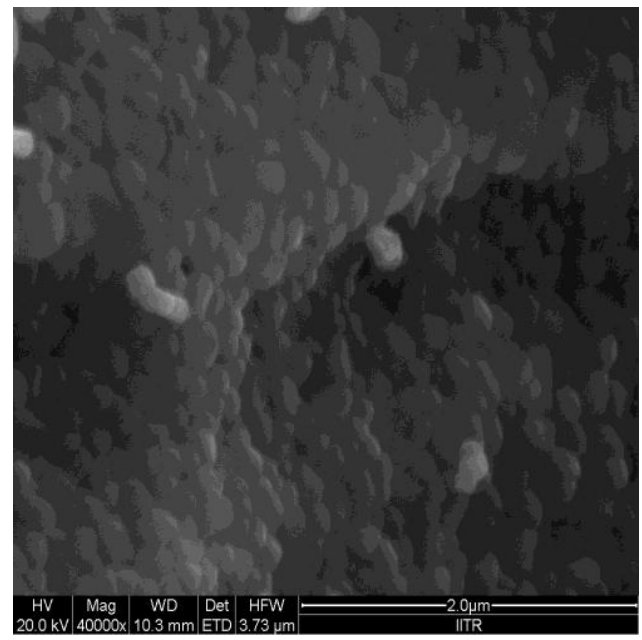

(c)

Fig 7: FE-SEM micrographs of Zn-ferrite calcined at (a) $600{ }^{\circ} \mathrm{C}$, (b) $700{ }^{\circ} \mathrm{C}$ and (c) $800{ }^{\circ} \mathrm{C}$

Fig. 8 shows the effect of calcination temperature on magnetic properties. Saturation magnetization and remanent magnetization decreases with increase in calcination temperature from 700 to $800{ }^{\circ} \mathrm{C}$. With the increase in calcination temperature this behavior may be attributed to the particle size in a manner that saturation magnetization is inversely dependent on the particle size. This behavior might be attributed to the presence of lattice defects, formed during powder preparation. Coercivity increases with the increase in temperature from 700 to $800{ }^{\circ} \mathrm{C}$ indicating that coercivity directly dependents on particle size.

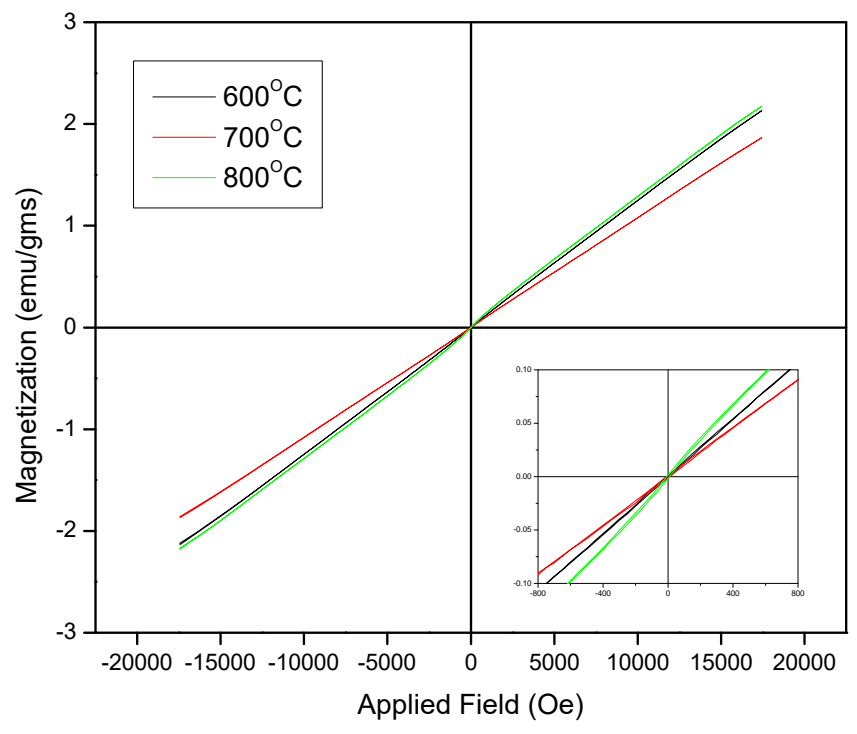

Fig 8: Effect of calcination temperatures on magnetic properties of $\mathrm{ZnFe}_{2} \mathrm{O}_{4}$

\section{CONCLUSION}

$\mathrm{ZnFe}_{2} \mathrm{O}_{4}$ powder was prepared by sol-gel method and the effect of solution $\mathrm{pH}$ and calcination temperature was observed on the phase formation and magnetic properties. It is observed from the results that the phase formation is sensitive of $\mathrm{pH}$ value. Pure spinel structure was observed from $\mathrm{pH}$ 9. Particle size also varies with $\mathrm{pH}$ variation (i.e. from $28 \mathrm{~nm}$ to $44 \mathrm{~nm}$ ), minimum particle size was observed against $\mathrm{pH}$ 7. SEM micrographs also confirm the formation of nano-sized particles. Pure spinel cubic structure was obtained at all the three calcination temperatures. It has been observed that with the increase in calcination temperature particle size increases. It may be concluded that magnetic properties are highly sensitive to the particle size. Saturation magnetization and remanent magnetization varies inversely with the particle size and coercivity depends directly on the size of particles. 


\section{REFERENCES}

[1] Y. Ahn and E.J. Choi, "Magnetization and Mossbauer Study of Nanosize ZnFe2O4 Particles Synthesized by Using a Microemulsion Method", Journal of the Korean Physical Society, Vol. 41, No. 1, July 2002, pp. 123-128.

[2] P. Laokul, V. Amornkitbamrung, S. Seraphin and S. Maensiri, "Characterization and magnetic properties of nanocrystalline $\mathrm{CuFe} 2 \mathrm{O} 4, \mathrm{NiFe} 2 \mathrm{O} 4, \mathrm{ZnFe} 2 \mathrm{O} 4$ powders prepared by the Aloe vera extract solution", Current Applied Physics, 2010, pp. 1-8.

[3] X.W. Qi, J. Zhou, Z.X. Yue, L.T. Li and Z.L. Gui, "Room Temperature Preparation of Nanocrystalline $\mathrm{MnCuZn}$ Ferrite Powder by Auto-Combustion of Nitrate-Citrate Gels", Key Engineering Materials, 2002, pp. 593-596.

[4] S. Maensiri, C. Masingboon, B. Boonchom and S. Seraphin, "A simple route to synthesize nickel ferrite (NiFe2O4) nanoparticles using egg white", Scripta Materialia, Vol. 56, 2007, pp. 797-800.

[5] B. Li, Z.X. Yue, X.W. Qi, J. Zhou, Z.L. Gui and L.T. $\mathrm{Li}$, "High $\mathrm{Mn}$ content $\mathrm{NiCuZn}$ ferrite for multiplayer chip inductor application", Materials Science and Engineering B99, 2003, pp. 252-254.

[6] E.J. Choi, Y. Ahn and E.J. Hahn, "Size Dependence of the Magnetic Properties in Super-paramagnetic Zinc-Ferrite Nanoparticles" Journal of the Korean Physical Society, Vol. 53, No. 4, 2008, pp. 20902094.

[7] J.M. Yang and F.S. Yen, "Evolution of intermediate phases in the synthesis of zinc ferrite nanopowders prepared by the tartrate precursor method", Journal of Alloys and Compounds, Vol. 450, 2008, pp. 387394.

[8] M.E. Abrishami, S.M. Hosseini and A. Kompany, "Effect of Calcination Process on Phase Formation in Nano-sized Zn0.9Mn0.1O Particles", Journal of Applied Sciences, Vol. 11, No. 8, 2011, pp. 14111413.

[9] O. Khamman, R. Yimnirun, and S. Ananta, "Effect of calcination conditions on phase formation and particle size of nickel niobate powders synthesized by solid-state reaction" Materials Letters, Vol. 61, 2007, pp. 639-643.

[10] A. Kumar, D. Singh and V. Agarwala, "Effect of particle size of $\mathrm{BaFe}_{12} \mathrm{O}_{19}$ on the microwave absorption characteristics in X-band", Progress in Electromagnetics Research M, Vol. 29, 2013, pp. 223-236. 